\title{
Grammitidaceae endémicas del Perú
}

\section{Blanca León ${ }^{1,2}$}

${ }^{1}$ Museo de Historia Natural, Av. Arenales 1256, Aptdo. 14-0434, Lima 14, Perú

2 Plant Resources Center, University of Texas at Austin, Austin TX 78712 EE.UU.

blanca.leon@mail.utexas.edu

\section{Resumen}

Los integrantes de esta familia fueron reconocidos por Tryon \& Stolze (1993) en la Tribu Grammitideae de la familia Polypodiaceae. Sin lugar a dudas, Grammitidaceae comparte estrecha afinidad con Polypodiaceae (Ranker et al., 2004; Schneider et al. 2004) y aquí se la reconoce como familia distinta. En el Perú, la familia Grammitidaceae está representada por nueve géneros y más de 80 especies (Tryon \& Stolze, 1993; Smith et al., 2005). Esta familia habita un amplio rango de altitudes y ambientes. Diez especies en tres géneros son endemismos conocidos principalmente de la región del Bosque Húmedo Montano, entre los 700 y $2500 \mathrm{~m}$ de altitud y de la Puna Seca y Húmeda, así como de la Alto Andina sobre los $3900 \mathrm{~m}$ de altitud. Cuatro de los endemismos cuentan con poblaciones en cinco áreas protegidas.

Palabras claves: Grammitidaceae, Perú, endemismo.

\section{Abstract}

Members of the Grammitidaceae were recognized by Tryon \& Stolze (1993) in the Tribe Grammitideae of the Polypodiaceae. Undoubtedly, Grammitidaceae shares close affinity with Polypodiaceae (Ranker et al., 2004; Schneider et al. 2004), but here is treated as a distinct family. In Peru, the family Grammitidaceae is represented by nine genera and more than 80 species (Tryon \& Stolze, 1993; Smith et al., 2005). This family occurs in a vast range of altitudes and environments. Ten species in three genera are recognized as endemics; they are found in the regions of the Humid Montane, and Premontane Forests, between 700 and 2500 m elevation, and also in the Dry and Humid Puna, and High Andean regions above $3900 \mathrm{~m}$ elevation. Four endemics are found in five protected areas.

Keywords: Grammitidaceae, Peru, endemism.

\section{Ceradenia congesta (Copel.) L.E. Bishop ex A.R. Sm.}

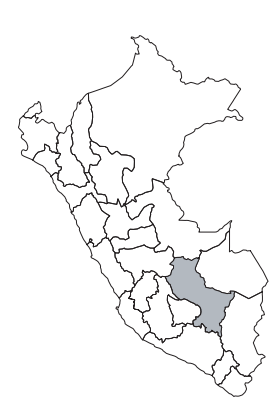

$$
\text { CR, B1ab(iii) }
$$

Publicación: Novon 3(2): 185. 1993.

Colección tipo: C. Bües 2172

Herbarios: US.

Nombre común: Desconocido,

Registro departamental: CU.

Regiones Ecológicas: PSH; 3900—4200

m.

SINANPE: Sin registro.

Herbarios peruanos: Ninguno.

Observaciones: Este helecho sólo se conoce de una recolección realizada en 1920, en una subcuenca del Urubamba. Probablemente, el tamaño reducido de la planta, contribuya a su casi inexistente registro. Por la altitud de la localidad se presume que esta especie habita en la zona de puna, la cual está sujeta a la quema con fines agrícolas y pecuarios.

\section{Ceradenia herrerae (Copel.) L.E. Bishop}

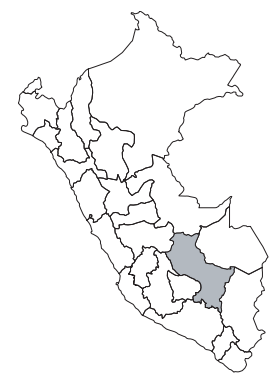

EN, B1a

Publicación: Amer. Fern J. 78: 4. 1988.

Colección tipo: C. Bües 1269

Herbarios: US; CUZ!.

Nombre común: Desconocido.

Registro departamental: CU.

Regiones Ecológicas: BPM, BMHM; 2750-3000 m.

SINANPE: Sin registro.

Herbarios peruanos: CUZ (isotipo).
Observaciones: Este helecho epífito sólo se conoce de dos ejemplares, uno de ellos estéril. Desde 1920, no ha vuelto a ser recolectada, pero tal vez se deba al hábito pequeño y a la poca atención a estas plantas. Probablemente estudios más detallados de los bosques montanos altos de la Provincia de la Convención puedan servir para confirmar el estatus de conservación de esta especie.

\section{Ceradenia longipinnata (Copel.) L.E. Bishop}

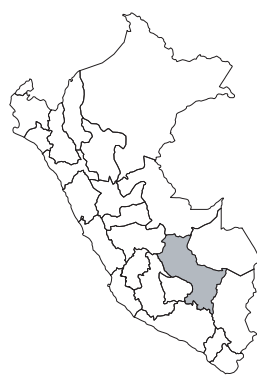

\section{EN, B1ab(iii)}

Publicación: Amer. Fern J. 78: 5. 1988.

Colección tipo: C. Bües 1952

Herbarios: US.

Nombre común: Desconocido.

Registro departamental: CU.

Regiones Ecológicas: BMHM; 2750$3250 \mathrm{~m}$.

SINANPE: Sin registro.

Herbarios peruanos: Ninguno.

Observaciones: Helecho epífito de hojas péndulas, conocido de las cuencas del Urubamba y Apurímac. Aparentemente no ha vuelto a ser recolectada desde 1976. Una población está cerca al Parque Nacional Otishi. Esta especie parece estar restringida a bosques montanos, los que en las cuencas conocidas están afectados por la deforestación. 
4. Ceradenia phalacron (Stolze) A.R. Sm.

\section{EN}

Publicación: Novon 5(1): 20. 1995.

Colección tipo: C. Bües A29

Herbarios: US.

Nombre común: Desconocido.

Registro departamental: CU.

Regiones Ecológicas: BMHM; 1800$2300 \mathrm{~m}$.

SINANPE: Sin registro.

Herbarios peruanos: Ninguno.

Observaciones: Helecho epífito,conocido de la cuenca del Urubamba. Probablemente, otras poblaciones se hallen en áreas aledañas, con remanentes boscosos. La falta de recolecciones recientes y la fuerte deforestación en el valle del Urubamba sugieren que esta especie está fuertemente amenazada.

\section{Ceradenia praeclara L.E. Bishop}

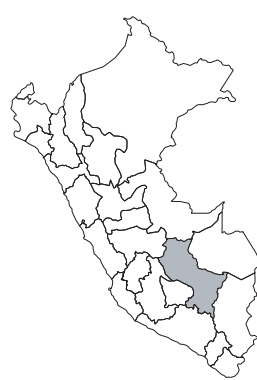

\section{CR, B1ab(iii)}

Publicación: Amer. Fern J. 79: 16. 1989. Colección tipo: C. Bües 2179

Herbarios: US.

Nombre común: Desconocido.

Registro departamental: CU.

Regiones Ecológicas: BMHM; $3150 \mathrm{~m}$.

SINANPE: Sin registro.

Herbarios peruanos: Ninguno.

Observaciones: Este helecho epífito, fue registrado de una subcuenca del Urubamba. Probablemente, como otras especies del género, sea una especialista de hábitat boscoso. Los bosques montanos a esa altitud, están fragmentados, son escasos y sujetos a quemas intencionales.

\section{Ceradenia terrestris L.E. Bishop}

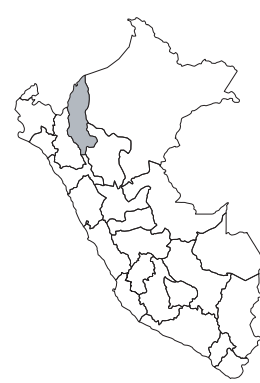

\section{EN}

Publicación: Amer. Fern J. 79: 23. 1989.

Colección tipo: J.J. Wurdack 1643

Herbarios: GH, US; USM!.

Nombre común: Desconocido.

Registro departamental: AM.

Regiones Ecológicas: MA; 2700—3100 m.

SINANPE: Sin registro.

Herbarios peruanos: USM (isotipo).

Observaciones: Este helecho terrestre se conoce solamente de una localidad. Weberbauer (1945) describe el área original como una zona ecológica intermedia entre bosques y matorrales húmedos montanos. Dada la tasa de deforestación en Amazonas, preocupa que no haya vuelto a ser registrada ahí.

\section{Ceradenia tryonorum B. León \& A.R. Sm.}

\section{EN, B1a}

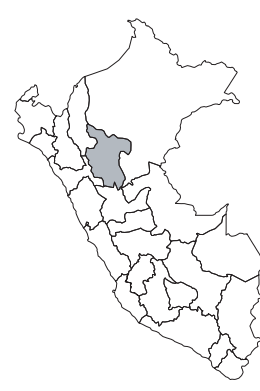

Publicación: Amer. Fern J. 93: 81, f. 1AD 2003.

Colección tipo: B. León \& K.R. Young 3840

Herbarios: TEX, UC; USM!.

Nombre común: Desconocido.

Registro departamental: SM.

Regiones Ecológicas: BMHM; $2800 \mathrm{~m}$.

SINANPE: PNRA

Herbarios peruanos: USM (holotipo).
Observaciones: Este helecho epífito se conoce, al parecer, sólo de una localidad, en la cuenca del Abiseo, un tributario del Huallaga. Esta única población conocida estaba integrada por pocos individuos, probablemente clonales. No se hallaron otras poblaciones en los alrededores.

\section{Melpomene gracilis (Hook.) A.R. Sm.}

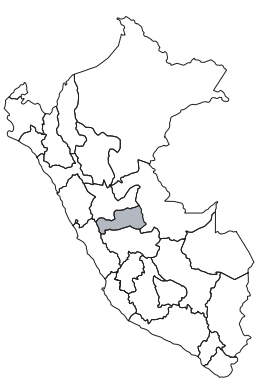

$$
\text { EN, B1a }
$$

Publicación: Novon 5(1): 21. 1995.

Colección tipo: A. Cruckshanks s.n.

Herbarios: GH, K.

Nombre común: Desconocido.

Registro departamental: PA.

Regiones Ecológicas: AA; $4500 \mathrm{~m}$.

SINANPE: SNH

Herbarios peruanos: Ninguno.

Observaciones: Esta especie terrestre se conoce solamente de una localidad y no ha vuelto a ser recolectada desde 1830. Por la geología de esta zona con rocas calizas, podría tratarse de una especialista de substrato. Su porte pequeño y hábitat contribuyan tal vez a la falta de colecciones de herbario de esta especie.

\section{Terpsichore bipinnata (Stolze) A.R. Sm.}

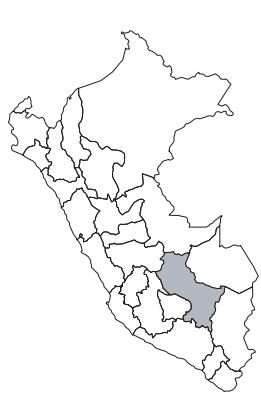

$$
\text { EN, B1ab(iii) }
$$

Publicación: Novon 5(1): 21. 1995.

Colección tipo: C. Bües 2167

Herbarios: F, US.

Nombre común: Desconocido.

Registro departamental: CU.

Regiones Ecológicas: PSH, BPM; 3150$4267 \mathrm{~m}$.

SINANPE: PNM, PNO

Herbarios peruanos: USM (2).

Observaciones: Este helecho epífito se conoce de cuatro localidades aisladas, en una subcuenca del Urubamba, asociadas a fragmentos de bosque ecotonales en ecotono con pajonales. $\mathrm{Al}$ parecer, no ha vuelto a ser herborizada desde 1934. Dos poblaciones adicionales se hallan en áreas protegidas y fueron herborizadas en la década de 1990.

\section{Terpsichore immixta (Stolze) A.R. Sm.}

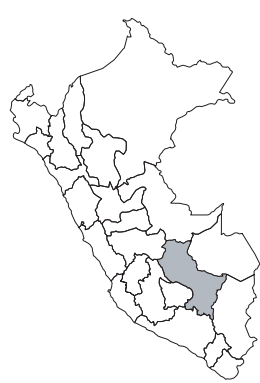

$$
\text { EN, B1a }
$$

Publicación: Novon 3(4): 487. 1993.

Colección tipo: C. Bües 2103

Herbarios: F, GH, MO, US; CUZ!.

Nombre común: Desconocido.

Registro departamental: CU.

Regiones Ecológicas: BMHM; $3650 \mathrm{~m}$. SINANPE: SHMP

Herbarios peruanos: CUZ (isotipo+1).

Observaciones: Helecho epífito, conocido de los bosques montanos húmedos, en las cuencas del Urubamba y Apurímac. La localidad original se halla al sur del Parque Nacional Otishi y podría encontrarse ahí. En 1985, fue recolectada del Santuario Histórico Machu Picchu. 